\title{
PENERAPAN ZPRENEUR DENGAN TEHNIK GAMIFIKASI BERUPA TRANSFER ARMO UNTUK MENINGKATKAN KUALITAS PEMBELAJARAN
}

\author{
Qurotul Aini ${ }^{1}$ \\ Danny Pratama ${ }^{2}$ \\ Novita Heriyani ${ }^{3}$ \\ Dosen STMIK Raharja ${ }^{1}$, STMIK Raharja Jurusan Sistem Informasi ${ }^{2,3}$ \\ Jl. Jendral Sudirman No. 40, Modernland, Kota Tangerang \\ Email: aini@raharja.info ${ }^{1)}$, danny.pratama@ raharja.info ${ }^{21}$, novita.heriyani@ raharja.info ${ }^{3)}$
}

\begin{abstract}
ABSTRAK
Seiring dengan perkembangan teknologi yang semakin cepat membuat para perguruan tinggi mulai meningkatkan daya saing dalam hal pendidikan teknologi dan informasi. Peningkatan yang sangat pesat dari tahun ke tahun membuat perguruan tinggi Raharja ingin selalu berinovasi, berkreasi dan membuat suatu inovasi yang bermanfaat bagi seluruh Pribadi Raharja. Banyak cara yang diampuh guna meningkatkan kualitas perkuliahan dalam proses pembelajaran, teknik gamifikasi dinilai mampu menjadi upaya guna meningkatkan kualitas perkuliahan dalam pembelajaran. ZPreneur mampu merealisasikan upaya tersebut, karena ZPreneur menerapkan teknik gamifikasi dengan menggunkan Armo (AirzonE-Mall Money) yang mampu membuat mahasiswa/i tidak merasa jenuh dan memberi perubahan pada aktifitas pembelajaran. Saat ini Perguruan Tinggi Raharja sudah menerapkan pembelajaran mengunakan konsep Gamifikasi melalui sebuah website ZPreneur. Ditambah lagi perancangan Viewboard Armo menjadi penyempurna karena semua user terangkum didalam semua viewboard armo dan akan memotivasi untuk para user agar selalu menjadi no 1 di dalam viewboar armo tersebut.
\end{abstract}

Kata Kunci: ZPreneur,Viewboard,Redeem Armo

\begin{abstract}
Along with the development of technology that the sooner make the College began to improve competitiveness in terms of technology and information education. Rapid improvement from year to year make Raharja College want to always innovate, be creative and make an innovation that will benefit the entire Personal Raharja.Many ways in which to improve the quality of forcibly lectures in the learning process, techniques gamifikasi judged capable of being an effort to enhance the quality of the lectures in the learning. ZPreneur is able to realize the effort, because the ZPreneur apply the technique of gamifikasi with either Armo (AirzonE-Mall Money) are able to make student/idon't feel saturated and give change in the learning activities. The College currently Raharja already apply the learning to use the concept of Gamifikasithrough a website ZPreneur. Plus the design Viewboard Armo became complete as all user embodied in all viewboard armo and will motivate the user to always be no. 1 in viewboar armo.
\end{abstract}

Keywoard: ZPreneur, Viewboard, Redeem Armo

\section{PENDAHULUAN}

Perkembangan ilmu pengetahuan yang sangat pesat diikuti oleh kemajuan teknologi informasi. Melalui teknologi informasi seseorang dapat memperoleh informasi dengan cepat dan mudah. Salah satu teknologi informasi yang cukup banyak digunakan saat ini adalah internet. Internet menghubungkan ribuan bahkan jutaan jaringan komputer diseluruh dunia, sehingga memungkinkan setiap komputer yang terhubung dapat melakukan komunikasi satu sama lain. Seluruh jaringan komputer dalam internet dapat saling berkomunikasi dengan 
menggunakan standar protokol yang secara resmi dikenal dengan TCP/IP ( Transmission Co ntrol Potocol/Internet Protocol ). Internet telah menyentuh berbagai sektor bidang kehidupan manusia mulai dari sektor bisnis, edukasi, entertain, dan lain sebagainya. Pemanfaatan internet dalam dunia pendidikan merupakan alat bantu yang cukup baik dalam memperbaiki sistem pembelajaran yang belum optimal.

Perguruan Tinggi Raharja merupkan salah satu institui pendidikan yang bergerak di bidang IT (Information Technology). Untuk itu, Perguruan Tinggi Raharja terus menerus melakukan peningkatan dan pengembangan berupa sistem pembelajaran dalam kampus yang ditetapkan di Perguruan Tinggi Raharja. Dengan adanya sistem pembelajaran online ini, mahasiswa/i diharapkan dapat memiliki wawasan yang lebih luas lagi. Dengan adanya sistem yang menunjang belajar sambil bermain akan membuat mahasiswa/i berfikir bahwa belajar tidak sejenuh yang diharapkan.

dikutip dari wikipedia ${ }^{[1]}$ website adalah suatu halaman web yang saling berhubungan atau berinteraksi yang umumnya berada pada peladen yang sama berisikan kumpulan informasi-informasi yang disediakan secara perorangan, kelompok, atau organisasi. Sebuah situs web biasanya ditempatkan setidaknya pada sebuah server web yang dapat diakses melalui jaringan seperti internet, ataupun jaringan wilayah lokal (LAN) melalui alamat Internet yang dikenali sebagai URL.

Jadi, website merupakan sekumpulan-sekumpulan informasi yang sangat berguna serta dibutuhkan oleh banyak orang di zaman ini. Dan dengan adanya website terciptalah pula komunitas-komunitas online dengan segala jenis informasi dan beragam bentuk yang bertebaran dalam dunia maya yang disuguhkan secara menarik.

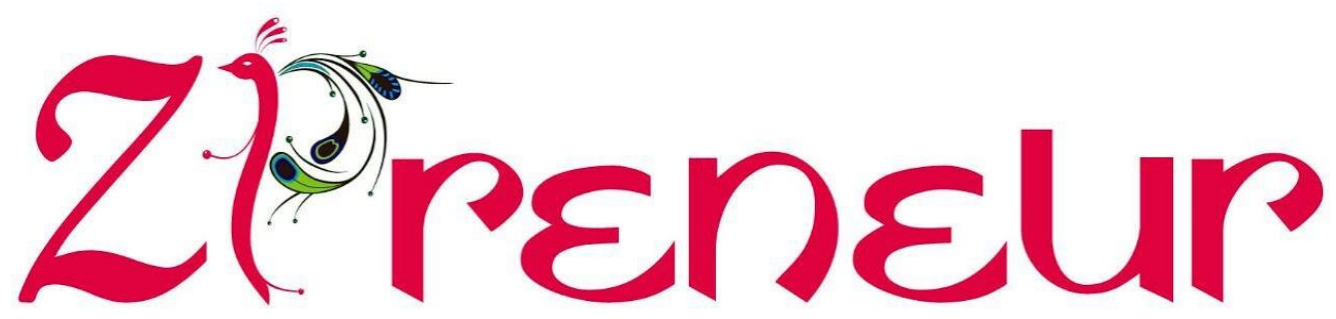

Gambar 1. Logo ZPreneur

\section{PERMASALAHAN}

Perguruan Tinggi Raharja yang biasa disebut Green Campus yang berperan di bidang Pendidikan Teknologi Perguruan Tinggi Raharja memiliki sebuah Website Komunitas Online. Dan berdasarkan yang dikemukakan oleh Bapak Untung Rahardja selaku Pimpinan Presiden Direktur Perguruan Tinggi Raharja Website Komunitas Online yang diberi nama ZPreneur Community. ZPreneur adalah sebuah Website Komunitas Online yang menjadi wadah berkumpulnya Mahasiswa/i yang ingin bertukar informasi, berdiskusi dan bertukar pikiran tentang dunia bisnis.

Why Z? Kata Z merupakan arti dari terpercaya dan memberikan dampak positif. Z yang berarti zero (nol) adalah awalan, yakni angka awal sebelum dimulainya kegiatan apapun, dan huruf $\mathrm{Z}$ juga merupakan bagian terakhir dalam abjad. Jika keduanya disatukan maka $\mathrm{Z}$ adalah permainan yang dimulai dari zero (nol) dan berakhir dalam huruf $\mathrm{Z}$. 


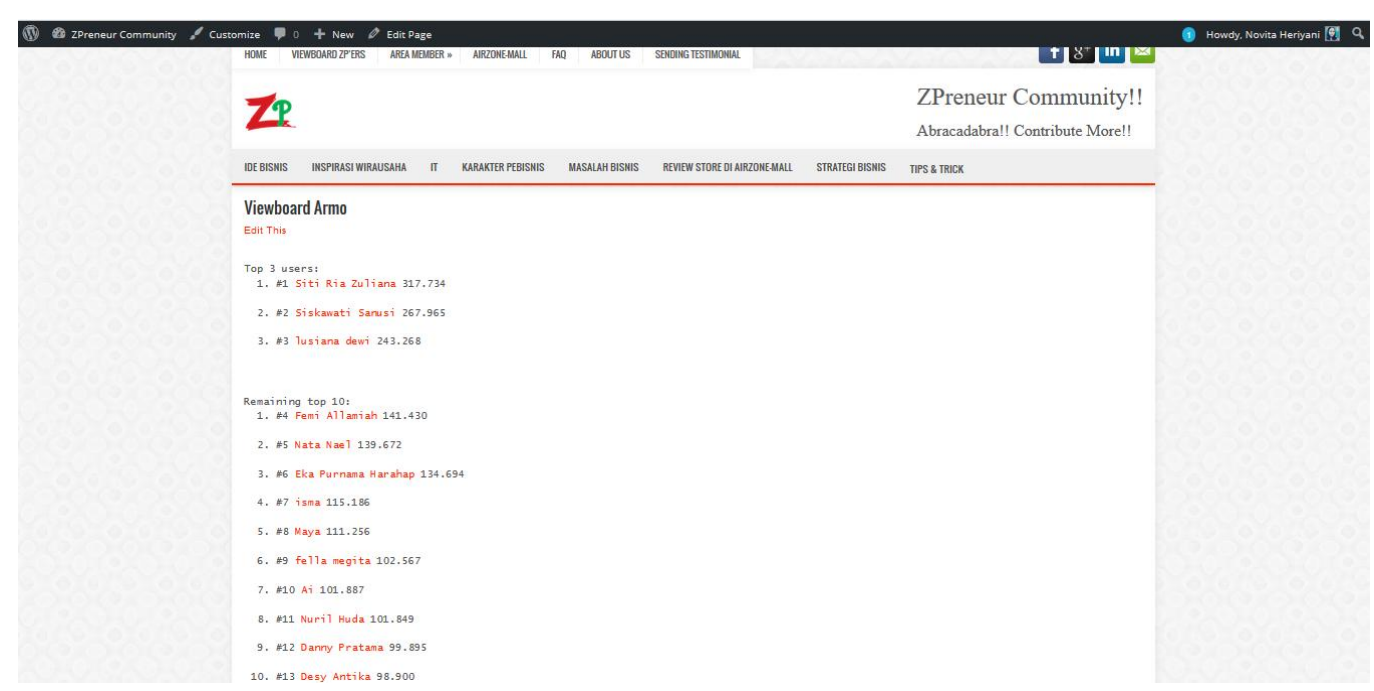

Gambar 2. Viewboard Armo

Berdasarkan permasalahan dan Analisa terhadap Viewboard Armo pada Website ZPreneur. Hal ini sangat terlihat bahwa team ZPreneur Community harus segera menyiapkan banyak strategi untuk melahirkan proses peningkatan keaktifan pada Viewboard Armo pada website ZPreneur. Seiring berjalannya waktu dan menggunakan banyak cara dan Strategi guna menaikan Rank Armo yang sampai saat ini cukup mengalami perkembangan yang cukup pesat. Namun seiring berjalannya waktu oleh karena itu berdasarkan analisa dari segi kekurangan serta kebutuhan terhadap sistem hendaknya bisa dituangkan pada poin-poin berikut:

1. Apakah Viewboard Armo di ZPreneur sudah efektif?

2. Apa saja informasi yang terdapat dalam Viewboard Armo?

3. Bagaimana Sistem Redeem Armo dapat bermanfaat untuk bertransaksi pada AirzonE-Mall?

\section{LITERATURE REVIEW}

Banyak penelitian yang sebelumnya dilakukan mengenai pemanfaatan teknologi informasi dan komunikasi dalam dunia pendidikan. Dengan memanfaatkan internet untuk mengeksplorasi pendidikan. Dalam upaya mengembangkan ZPreuner ini perlu dilakukan studi pustaka sebagai salah satu dari penerapan metode penelitian yang akan dilakukan. Diantaranya adalah mengidentifikasikan kesenjangan (identify gaps), menghindari pembuatan ulang (reinventing the wheel), mengidentifikasikan metode yang pernah dilakukan, meneruskan penelitian sebelumnya, serta mengetahui orang lain yang spesialisasi dan area penelitiannya sama dibidang ini. Beberapa Literature review tersebut adalah sebagai berikut :

1. Penelitian ini dilakukan oleh Untung Rahardja, Qurotul Aini dan Desi Sartika dari Perguruan Tinggi Raharja pada tahun 2014 yang berjudul "Build A Business To Consumer Online Store Using Airzone Content Management System". Penelitian ini membahas mengenai Sistem Jual Beli Online Airzone yang menerapkan Sistem ECommerce yang menghubungkan antara 4 (empat) Klasifikasi E-Commerce menurut pola interaksi atau transaksi yaitu Costumer-to-Business (C2B), Business-to-Costumer (B2C), Business-to-Business (B2B) dan Peer-to-Peer (P2P). Dengan adanya Sistem ECommerce tersebut mempermudah konsumen dan masyarakat untuk berbelanja secara online di Airzone menjadi lebih Efektif dan Efisien. 
2. Penelitian ini dilakukan oleh Iwan Hermawan dari Politeknik Negeri Semarang pada tahun 2011 yang berjudul "Rancangan Pembelajaran Interaktif Mata Kuliah Ecommerce Melalui Pembuatan Software Bantu Pengajaran Berbasis Multimedia". Penelitian ini membahas mengenai pemanfaatan teknologi yang dikemas ke dalam sebuah set perangkat multimedia yang dapat digunakan untuk bahan ajar pada mata kuliah ECommerce. Arah dari dikembangkannya perangkat modul digital adalah untuk menunjang perubahan kurikulum berupa penajaman mata kuliah untuk mendapat aspek kognitifedukatif.

3. Penelitian ini dilakukan oleh Padeli, Sudaryono dan Indri Handayani dari Perguruan Tinggi Raharja pada tahun 2014 yang berjudul "Building Marketing Untuk Komunitas Sendiri Berbasis Online". Penelitian ini membahas mengenai Program yang dapat memberikan kemudahan kepada konsumen dalam mencari dan membeli produk produk yang dijual oleh Bizarre Sounds Production, agar penjualan, pemesanan dan informasi servis barang menjadi lebih baik dan Informasi yang ditampilkan tidak hanya berita - berita seputar dunia musik metal tetapi juga promosi-promosi terbaru dari produk Bizarre Sounds Production agar dapat meningkatkan penjualan dan keuntungan dari perusahaan.

4. Penelitian ini dilakukan oleh Untung Rahardja, Sudaryono dan Irwan Nurdin dari Perguruan Tinggi Raharja pada tahun 2014 yang berjudul "Implementasi IME (iLearning Media) dalam medukung sistem pembelajaran iLearning pada Perguruan Tinggi". Penelitian ini membahas mengenai sistem pembelajaran iLearning pada Perguruan Tinggi Raharja. Sistem iLearning adalah metode perkuliahan di Perguruan Tinggi Raharja yang menggunakan media iPad untuk mempermudah proses pembelajaran mahasiswa. Dengan adanya metode ini maka mahasiswa dapat belajar, bekerja, berdoa dan bermain dengan iPad. Istilah tersebut dikenal,dengan nama 4B. iLearning Media atau disingkat dengan nama iMe adalah aplikasi berupa site yang dibuat dan dapat digunakan oleh seluruh mahasiswa Perguruan Tinggi Raharja untuk mengeksplor kreativitasnya dalam belajar. Ini merupakan sistem pembelajaran online yang memudahkan mahasiswa dalam belajar, karena dapat dilakukan di manapun dan kapanpun. Maka disimpulkan bahwa kontribusi iMe dapat dijadikan media informasi untuk sistem pembelajaran bagi seluruh civitas Perguruan Tinggi Raharja.

5. Penelitian ini dilakukan oleh Henderi, Untung Rahardja, Qory Oktisa Aulia dan Muhamad Hendri pada tahun 2011 yang berjudul "Dashboarding Information Systems For The Education Sector: Aplication and Methodologies". Penelitian ini membahas metodologi dan aplikasi dashboarding information system (DIS) untuk institusi sektor pendidikan sebagai model sistem informasi pengukuran dan evaluasi capaian kinerja organisasi dalam bentuk key performance indicator (KPI). Dalam implementasinya, aplikasi DIS dibangun menggunakan bahasa pemograman PHP untuk membuat aplikasi front office sebagai interface dan software fusionchart sebagai aplikasi pembuat grafik. Aplikasi DIS yang dibuat juga menggunakan eXtensible Markup Language (XML).

6. Penelitian yang dilakukan oleh Eka Purnama Harahap (2015). Penelitian ini mengenai "Analisa Manajemen Sistem Gamifikasi ZPreneur Sebagai Inovasi Pembelajaran Pada Perguruan Tinggi" Dalam penelitian ini, peneliti membahas sistem pembelajaran online untuk pembelajaran entrepreuneurship. Peneliti mengembangkan sebuah forum/komunitas ZPreneur yang berkonsep gamifikasi yaitu belajar dan bermain, yang bertujuan untuk menampung semua kreativitas mahasiswa-mahasiswi dalam kewirausahaan dan untuk membuat mahasiswa-mahasiswi tidak jenuh dalam proses pembelajaran tersebut. 
7. Penelitian yang dilakukan oleh Untung Rahardja, Hidayati, Mia Novalia (2011). Penelitian ini mengenai "Peningkatan Kinerja Distributed DataBase Melalui Methode DMQ Base Level". Dengan melakukan penerapan metode DMQ base level berikut ini merupakan 4 (empat) ciri khas dari metode DMQ base levelyang diterapkan pada proses view jadwal rencana study (JRS). Yang pertama informasi yang dibutuhkan bersifat WORT (Write Once ReadThousand). Kedua sesuai dengan standar TWT (Tolerable Wait Time).Ketiga adanya pemisahan antara "Engine" dan "Display". Keempat mengorbankan harddisk untuk meninggalkan kecepatan. Berdasarkan uraian diatas, dapat disimpulkan bahwa Data Mart Query (DMQ) base levelsangat tepat digunakan untuk mempercepat waktu proses view data bagi informasi WORT. Metode ini digunakan untuk menghindari penggunaan Querymajemuk karena banyak data yang tersebar dalam suatu sistem databaseyang terdistribusi, sehingga terjadi query besarbesaran pada saatsetiap kali membutuhkan data. Dengan menggunakan DMQ base level ini, memungkinkan sebuah display data dapat ditampilkan dengan sangat cepat. Sehingga telah dibuktikan bahwa metode ini sesuai dengan standar TWT, yang dapat memenuhi kenyamanan pengguna dari segi response time.

Dari 7 (Tujuh) literature review yang ada, telah banyak penelitian mengenai Peningkatan Web Rank. Namun dapat disimpulkan pula bahwa belum ada peneliti yang secara khusus membahas mengenai Penerapan Teknik Gamifikasi Dalam Bentuk Sending Gifts Untuk Meningkatkan Traffic Rank. Sebagai Komunitas online ZPreneur ingin menumbuhkan tingkat Mahasiswa/i dalam mengembangkan minat serta bakatnya di bidang Bisnis dengan menggunakan Teknik Gamifikasi dalam Bentuk Sending Gifts sehingga membuat Mahasiswa/i betah untuk berkontribusi di dalam ZPreneur Community.

\section{PEMECAHAN MASALAH}

Perguruan Tinggi Raharja sebagai sebuah institusi yang bergerak di dalam bidang Pendidikan Teknologi, Diharapkan mampu mempunyai sebuah Website Komunitas Online. Kemudian dicetuskan lah oleh Bapak Untung Rahardja selaku Pimpinan Presiden Perguruan Tinggi Raharja sebuah Website Komunitas Online yang diberi nama ZPreneur Community. ZPreneur adalah sebuah Website Komunitas Online yang menjadi wadah berkumpulnya Mahasiswa/i yang ingin bertukar pikiran, berdiskusi dan mencari informasi tentang dunia bisnis.

Sistem Zpreneur yang dikembangkan oleh Perguruan Tinggi Raharja bertujuan untuk memenuhi aktivitas kegiatan mahasiswa dalam melakukan kegiatan pembelajaran entrepreneurship. Dengan bantuan sistem tersebut, memudahkan mereka dalam melakukan aktivitas didalam ZPreneur. 


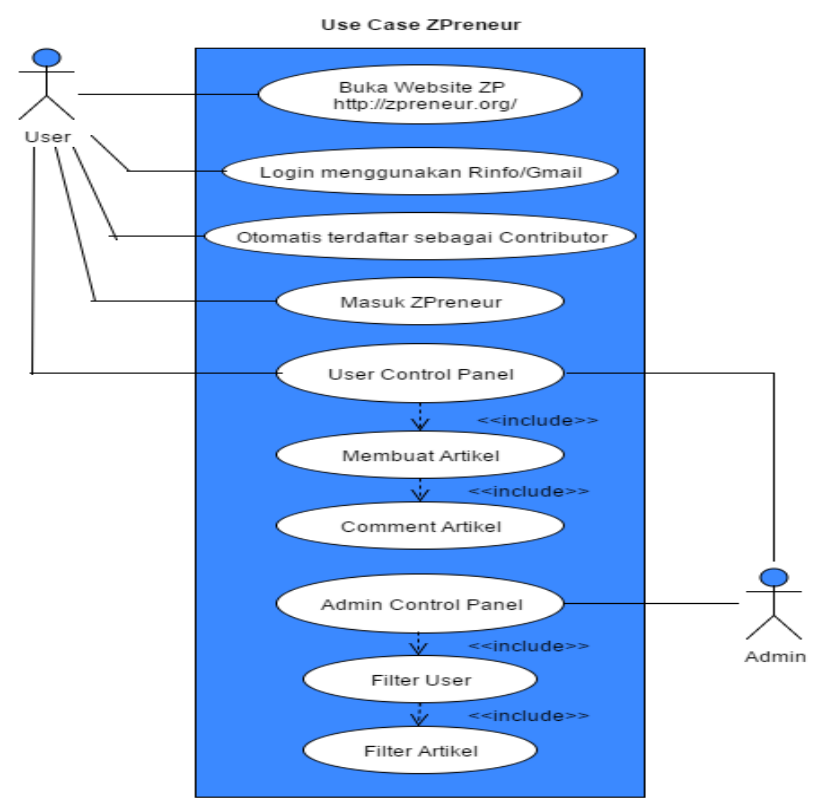

Gambar 3. Use Case Metode Pembelajaran ZPreneur

Setelah mengamati dari sudut permasalahan yang telah terjadi di dalam sistem yang sudah berjalan dan penulis memiliki beberapa pilihan alternatif pemecahan masalah pada sistem yang berjalan, yaitu sebagai berikut:

1. Menciptakan sistem ZPreneur sebagai pembelajaran baru yang lebih menarik dengan adanya sistem Redeem Armo yang dapat menunjang kebutuhan, menumbuhkan minat dan motivasi belajar mahasiswa/i yang ada di Perguruan Tinggi Raharja.

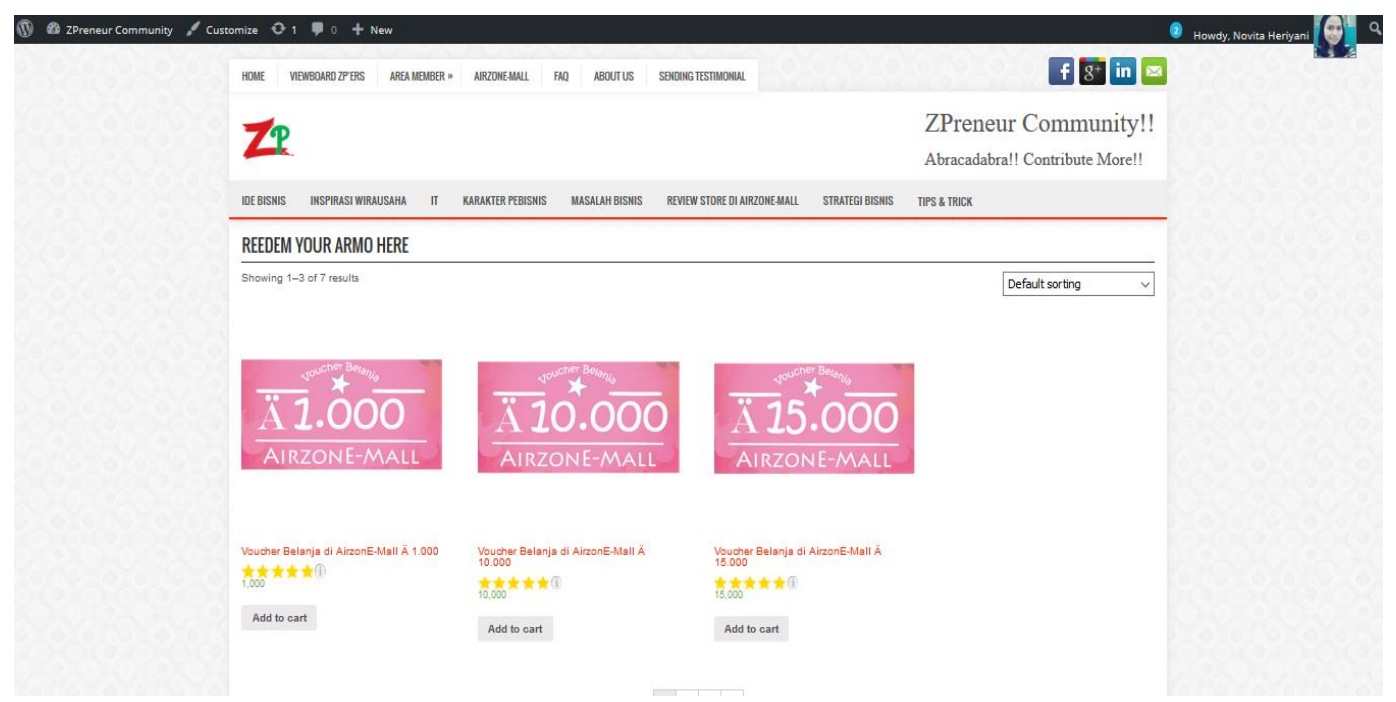

Gambar 4. Redeem Armo

2. Menerapkan Viewboard Armo pada website ZPreneur agar bisa memantau setiap saat naik turunnya Rank Armo pada website ZPreneur Community.

Keistimewaan ZPreneur 
ZPreneur Community adalah Komunitas yang berada di Perguruan Tinggi Raharja. Halhal yang terdapat didalamnya menyajikan informasi yang berhubungan dengan Entrepreneurship yang menjadi wadah atau tempat untuk bertukar informasi tentang Bisnis, hobi atau berdiskusi antar Pribadi Raharja. Maka lahirlah beberapa Keistimewaan dari Komunitas ZPreneur yaitu:

1. Login menggunakan SSO (Single Sign On)

2. Memiliki mata uang sendiri yaitu Armo

3. Kumpulan Artikel mengenai Dunia Bisnis (Entrepreneurship)

4. Fitur Gamification (Add Friends, Update Status, Send Gifts)

5. Memiliki AirzonE-Mall

\section{Tujuan ZPreneur}

Terciptanya sebuah website ZPreneur Community ini bertujuan untuk menjadi wadah/tempat diskusi dan bertukar informasi bagi para Pribadi Raharja. Dan untuk meningkatkan minat menulis dan membaca bagi para Pribadi Raharja, dan untuk meningkatkan wawasan dan pengetahuan seputar dunia bisnis, sehingga dapat mengembangkan kreatifitas Pribadi Raharja didalam dunia Bisnis, untuk mendapatkan informasi mengenai Entrepreneurship didalam Artikel ZPreneur Community,

\section{Definisi Armo}

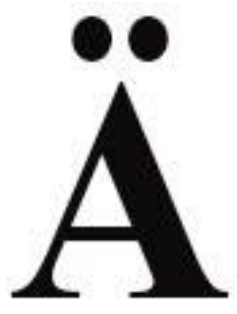

Gambar 5. Logo Armo

Armo (AirzonE Money) merupakan mata uang AirzonE-Mall yang terdapat di dalam ZPreneur yang diciptakan oleh mahasiswa Perguruan Tinggi Raharja. Armo (AirzonE Money) tercipta karena terinspirasi dari sebuah permainan monopoli, awal mula AirzonE-Mall ingin mempunyai mata uang seperti yang dimiliki permainan monopoli yang memiliki mata uang sendiri yang ditaruh di bank dari situlah mata uang AirzonE-Mall lahir lalu diberi nama Armo. Dengan adanya Armo diharapkan dapat memudahkan para pelajar untuk bisa bertransaksi di AirzonE-Mall dan Armo menjadi ciri khas tersendiri untuk AirzonE-Mall dan ZPreneur. Dan terdapat ketentuan untuk mendapatkan Armo yaitu seperti Membuat Artikel, Comment Artikel, Sending Gift dan Like Artikel mendapatkan 100 Armo, sedangkan Jika para ZP'ers membuat Artikel atau melakukan kegiatan Sending Gifts maka akan mendapatkan masing-masing 500 Armo.

\section{IMPLEMENTASI}

Tampilan implementasi aplikasi ZPreneur memiliki berbagai macam fitur yang dapat digunakan oleh para ZP'ers. Tampilan Armo ZPreneur yang dapat dilihat oleh ZP'er utuk melihat seberapa banyak Armo yang dimiliki. 


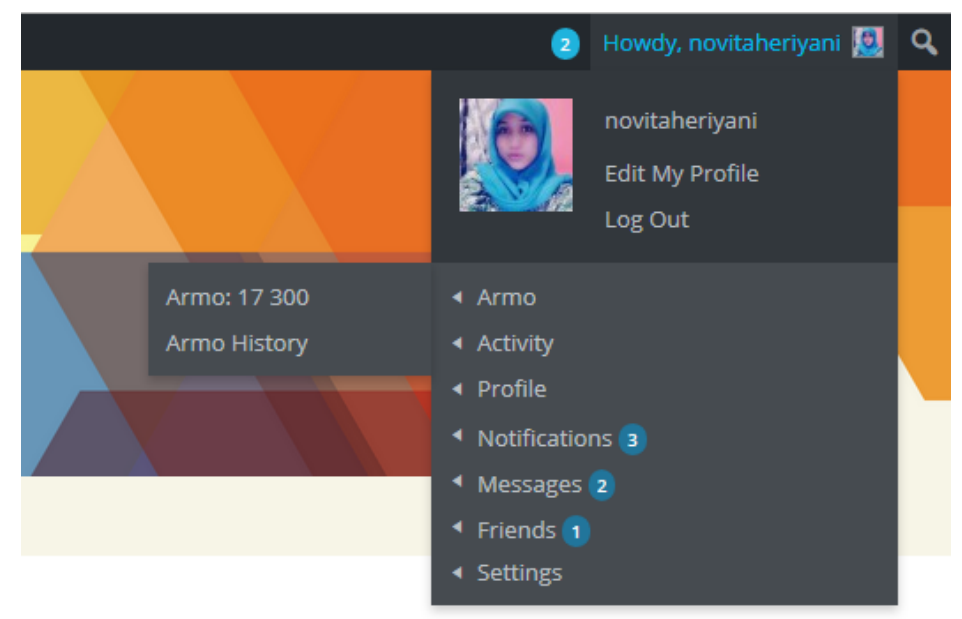

Gambar 6.Tampilan Armo ZPreneur

1. Jika kalian telah registrasi, otomatis Armo kalian bertambah $\ddot{A} 10.000$

2. Setiap berkunjung per hari, otomatis Armo akan bertambah $\ddot{A} 100$

3. Satiap melihat post, otomatis Armo akan bertambah $\ddot{A} 100$

4. Setiap melihat page, Armo akan bertambah $\ddot{A} 100$

5. Setiap log in kedalam ZPreneur maka Armo akan bertambah Ä500 per hari.

6. Setiap memposting artikel di zpreneur akan mendapatkan Armo. Dengan memposting sebuah artikel bisa mendapatkan Armo sebanyak Ä500 dengan limit 10x per hari

7. Setiap memberikan comment di artikel di zpreneur kalian pun akan mendapatkan Armo. Dengan itu kalian bisa mendapatkan Armo sebanyak Ä100 untuk comment yang approved. Jika comment tidak ter-approved atau mark as spam maka akan ada pengurangan Armo sebesar - Ä100 limit 10x per hari.

8. Setiap kalian menklik 1 (satu) link yang ada di zpreneur. Armo kalian akan bertambah Ä500 dan tak ada limitnya.

9. Meng-update profile akan menambah Armo kalian sebanyak $\ddot{A} 100$ per hari.

10. Mengubah avatar akan menambahkan Armo kalian sebanyak $\ddot{A} 300$ per hari.

- Transfer Armo: Berisikan tentang bagaimana cara mengirimkan Armo kepada para ZP'ers

- Reedem: Berisikan tentang bagaimana cara Meredeem Armo untuk ditukarkan menjadi Voucher Belanja di AirzonE-Mall. 


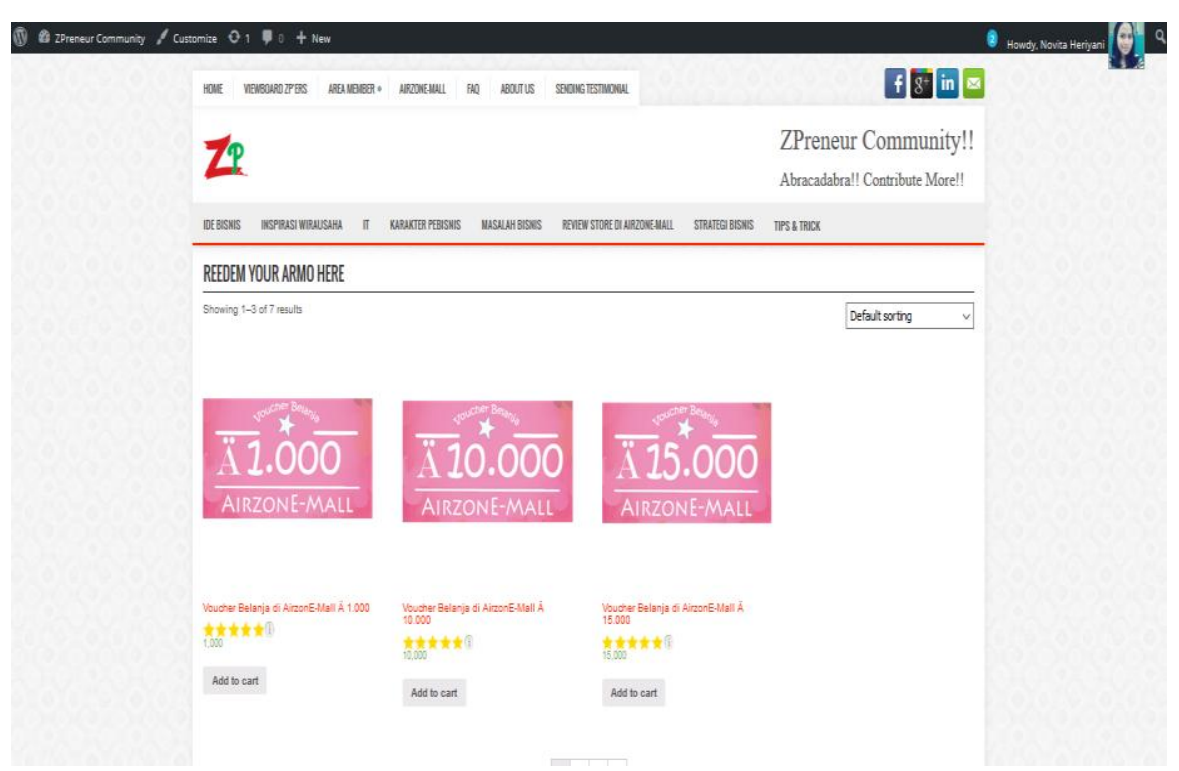

Gambar 10. Tampilan Menu Redeem Armo ZPreneur.

5. AirzonE-Mall: Berisikan Mall yang didalamnya terdapat berbagai macam produk pilihan (http://airzone.zpreneur.org/).

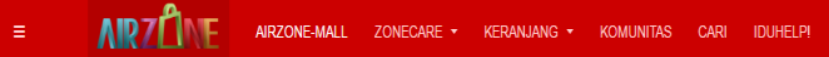

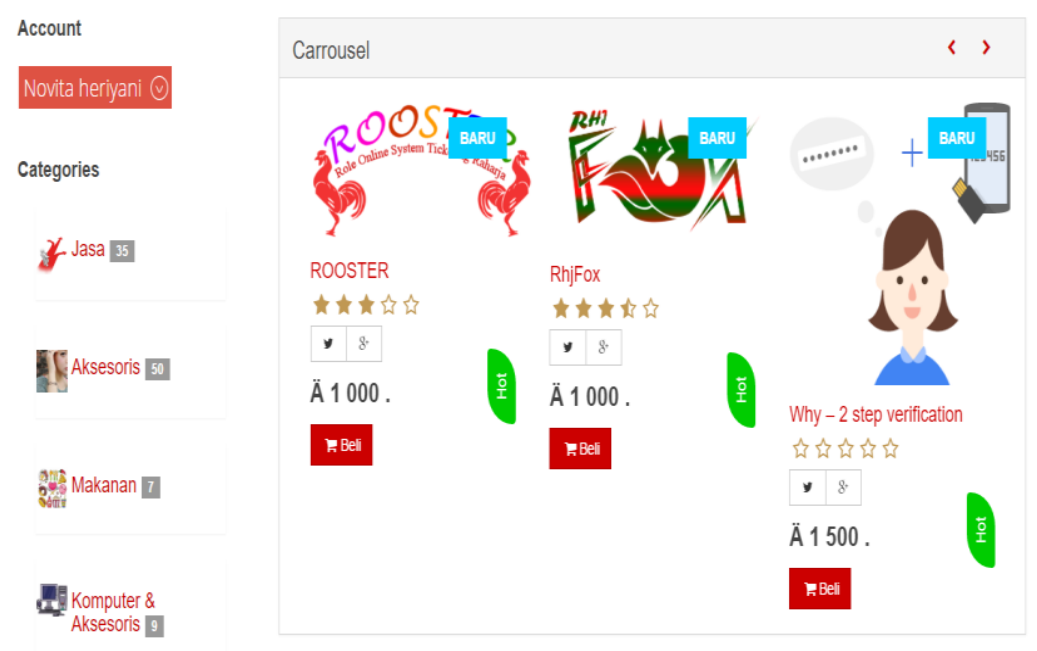

Gambar 11. Tampilan utama AirzonE-Mall 
6. FAQ: Berisikan Kumpulan tentang tutorial atau langkah-langkah bermain di dalam ZPreneur.

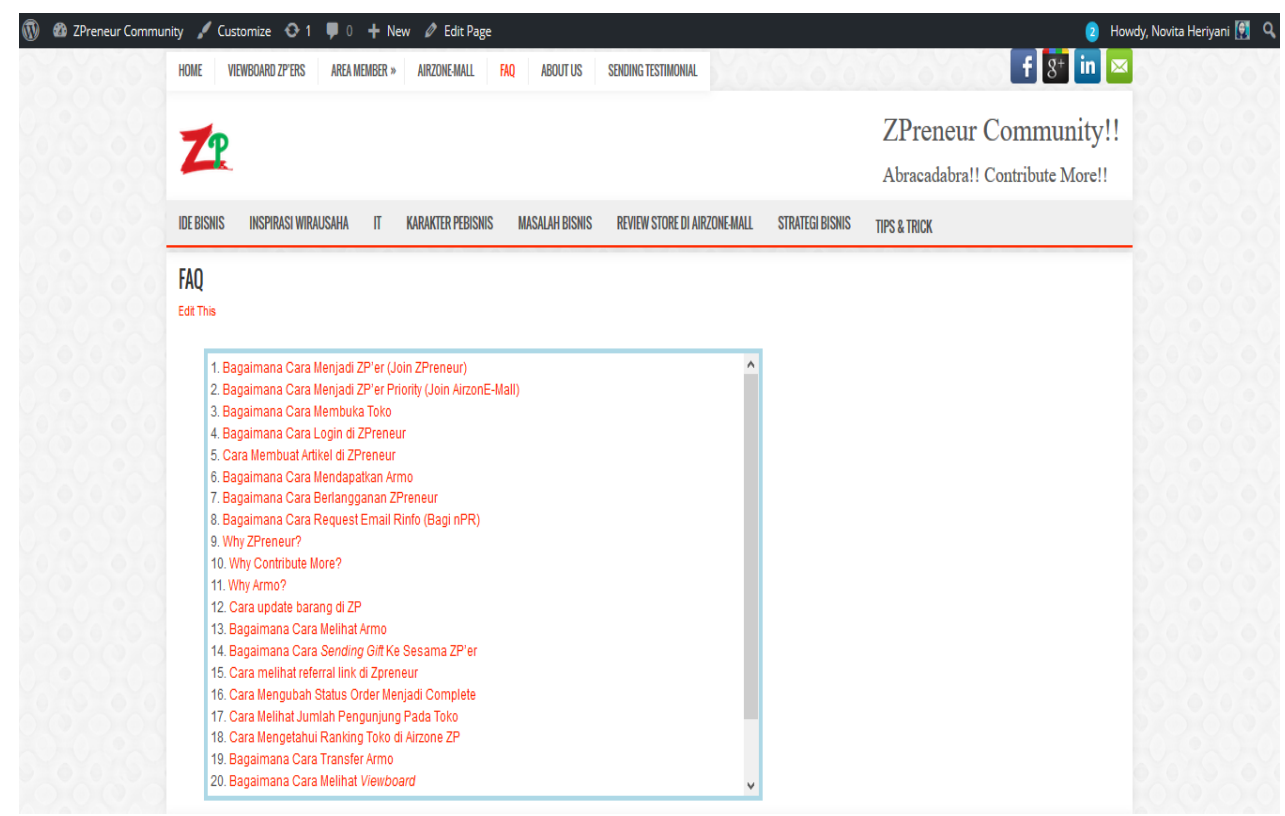

Gambar 12. Tampilan FAQ ZPreneur Community

7. About Us: Berisikan tentang Visi dan Misi website ZPreneur.

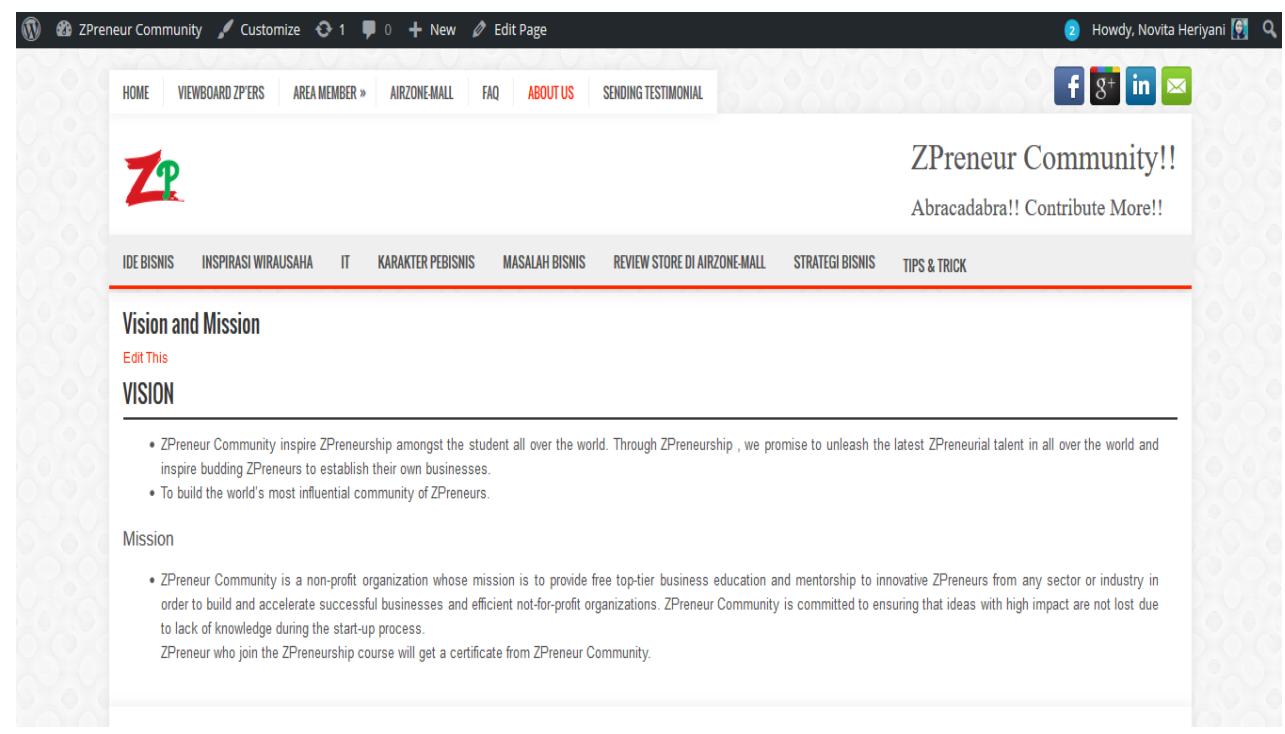

Gambar 13. Tampilan About Us ZPreneur.

\section{KESIMPULAN}

Dengan demikian dapat disimpulkan bahwa dengan adanya teknik gamifikasi yang berupa Armo sebagai hasil dari aktifitas yang mereka kerjakan di dalam ZPreneur diharapkan menjadi innovasi pembelajaran yang dapat membuat mahasiswa/i lebih terpacu dan semangat dalam menjalankan proses pembelajaran dan perkuliahan dengan lebih menyenangkan serta dengan adanya Armo yang terlihat lebih bermanfaat serta fungsinya tentu sudah menjadi upaya yang tepat dalam meningkatkan kualitas perkuliaha pada Perguruan Tinggi Raharja. Armo menjadi ciri khas tersendiri untuk AirzonE-Mall dan ZPreneur. Dan terdapat ketentuan 
untuk mendapatkan Armo yaitu seperti Membuat Artikel, Comment Artikel, Sending Gift dan Like Artikel yang akan mendapatkan 100 Armo, sedangkan Jika para ZP'ers membuat Artikel atau melakukan kegiatan Sending Gifts maka akan mendapatkan masing-masing 500 Armo.

Dengan adanya Armo akan membuat minat mahasiswa/i menulis dan membaca menjadi meningkat karena aktivitasnya mendapatkan hadiah berupa Armo (AirzonE-Money), yang dapat ditukar atau di Redeem ke AirzonE-Mall untuk bertransaksi di AirzonE-Mall, dan yang terakhir untuk menjadi wadah/tempat diskusi dan bertukar informasi bagi para Pribadi Raharja. Hasil yang diharapkan dari mahasiswa/i yang menjalani pembelajaran dengan teknik gamifikasi ZPreneur berupa Armo adalah memacu semangat mahasiswa agar tidak jenuh dalam mengikuti pembelajaran perkuliahan sehingga proses belajar dan mangajar lebih menyenangkan.

\section{DAFTAR PUSTAKA}

[1] Widuri. Zpreneur. Diakses pada tanggal 1 Desember 2015. Tersedia di http://widuri.raharja.info/index.php?title=ZPREUNER

[2] Rahardja, Untung, Qurotul Aini, and Desi Sartika. "BUILD A BUSINESS TO CUSTOMER ONLINE STORE USING AIRZONE CONTENT MANAGEMENT SYSTEM."

[3] Hermawan Iwan "Rancangan Pembelajaran Interaktif Mata Kuliah Ecommerce Melalui Pembuatan Software Bantu Pengajaran Berbasis Multimedia", 2011. Politeknik Negeri Semarang. [2] Hidayati Novi "Sistem ELearning Untuk Meningkatkan Proses Belajar Mengajar.

[4] Padeli, Sudaryono dan Indri Handayani. CCIT Journal 2014. Building Marketing Untuk Komunitas Sendiri Berbasis Online. Perguruan Tinggi Raharja.

[5] Rahardja Untung, Sudaryono, Nurdin Irwan "Implementasi IME (iLearning Media) dalam medukung sistem pembelajaran iLearning pada Perguruan Tinggi”, 2014, Perguruan Tinggi Raharja.

[6] Henderi, Untung Rahardja, Qory Oktisa Aulia dan Muhamad Hendri. 2011. "Dashboarding Information Systems For The Education Sector: Aplication and Methodologies".

[7] Harahap, Eka Purnama, Laporan KKP 2015. "Analisa Manajemen Sistem Gamifikasi ZPreneur Sebagai Inovasi Pembelajaran iLearning Pada Perguruan Tinggi"

[8] Untung, R, and N Mia. "Hidayati."Peningkatan Kinerja Distributed Database Melalui Methode DMQ Base Level”." CCIT Journal ISSN 8282 (1978).

[9] Widuri. Armo. Diakses pada tanggal 8 Desember 2016. Tersedia di http://widuri.raharja.info/index.php?title=Armo 